\title{
The Maritime Declaration of Health (MDH) as a tool to detect maritime traffic-related health risks: analysis of MDH forms submitted to Spanish ports, October 2014 to March 2015
}

RM López-Gigosos ${ }^{1}$, M Segura ${ }^{1}$, RM Díez-Díaz ${ }^{1}$, I Ureña ${ }^{1}$, D Urzay ${ }^{2}$, P Guillot ${ }^{2}$, A Guerra-Neira ${ }^{3}$, A Rivera ${ }^{3}$, Á Pérez-

Cobaleda ${ }^{4}$, A Martín ${ }^{4}$, M Nuñez-Torrón ${ }^{5}$, B Alvarez ${ }^{5}$, M Faraco ${ }^{6}$, JM Barrera ${ }^{6}$, MJ Calvo ${ }^{7}$, J Gallegos ${ }^{8}$, A Bermejo ${ }^{8}$, C

Aramburu ${ }^{9}, M_{\text {Dávila }}{ }^{10}, \mathrm{~F}_{\text {Carreras }}{ }^{10}, \mathrm{R}$ Neipp ${ }^{10}$, A Mariscal $^{11}$

1. Medical service, Port Health Authority of Málaga, Málaga, Spain

2. Medical service, Port Health Authority of Tarragona, Tarragona, Spain

3. Medical service, Port Health Authority of Tenerife, Santa Cruz de Tenerife, Spain

4. Medical service, Port Health Authority of A Coruña, A Coruña, Spain

5. Medical service, Port Health Authority of Vigo, Vigo, Spain

6. Medical service, Port Health Authority of Huelva, Huelva, Spain

7. Medical service, Port Health Authority of Santander, Santander, Spain

8. Medical service, Port Health Authority of Algeciras, Algeciras, Spain

9. Medical service, Port Health Authority of Barcelona, Barcelona, Spain

10. Subdirección General de Sanidad Exterior, Ministry of Health, Madrid, Spain

11. Department of Public Health, University of Málaga, Málaga, Spain

Correspondence: Rosa Lopez-Gigosos (gigosos@uma.es)

The international maritime traffic of people and goods has often contributed to the spread of pathogens affecting public health. The Maritime Declaration of Health $(\mathrm{MDH})$, according to the International Health Regulations (IHR) (2005), is a document containing data related to the state of health on board a ship during passage and on arrival at port. It is a useful tool for early detection of public health risks. The main objective of our study was to evaluate compliance with the model provided in the IHR, focusing on the format and degree of completion of $\mathrm{MDH}$ forms received at Spanish ports. We reviewed the content of 802 MDH forms submitted to nine Spanish ports between October 2014 and March 2015. Study results show that $22 \%$ of MDH forms presented did not comply with the recommended model and $39 \%$ were incomplete. The proportion of cargo ships with correct and complete MDH forms was lower than passenger ships; thus, the nine health questions were answered less frequently by cargo ships than passenger ships (63\% vs $90 \%$, p value $(0.001)$. The appropriate demand and usage of MDH forms by competent authorities should improve the quality of the document as a tool and improve risk assessment.

\section{Introduction}

In today's interdependent and interconnected world, it is possible for diseases to spread rapidly across the world and threaten public health. This is possible because of highly mobile human populations, international transport and trade. International public health security depends on the appropriate management of public health risks, which in turn depend on national capacities and international collaboration $[1,2]$. Effective public health measures and response capacities at airports, ports and ground crossings worldwide reduce the risk of the international spread of disease [3-5].

The International Health Regulations (IHR) (2005) [6] is a key international public health document that is legally binding across 196 countries, including all World Health Organization (WHO) Member States, requiring them to work together for global health security. This fundamental document requires that ratifying countries have the ability to detect, assess, report and respond to public health events $[7,8]$.

The IHR (2005) includes provisions for the use of various health documents that can be presented, if requested, to health authorities on arrival at ports and airports [9]: the Ship Sanitation Certificate (Annex 3), the International Certificate of Vaccination and Prophylaxis (Annex 6), the Maritime Declaration of Health (MDH) (Annex 8) and the Health Part of the Aircraft General Declaration (Annex 9). If these 
TABLE 1

Number of analysed Maritime Declaration of Health forms from different ports of call, Spain, October 2014 to March 2015 $(\mathrm{n}=802)$

\begin{tabular}{|l|c|c|}
\hline The ports and their geographical area & Number of MDH forms (n) & Percentage of total (\%) \\
\hline Atlantic Ocean ports on the northern coast & $\mathbf{2 0 9}$ & $\mathbf{2 6}$ \\
\hline A Coruña & 101 & 3 \\
\hline Santander & 27 & 10 \\
\hline Vigo & 81 & $\mathbf{3 6}$ \\
\hline Atlantic Ocean ports on the southern coasts and the Canary Islands & $\mathbf{2 8 5}$ & 12 \\
\hline Algeciras & 93 & 12 \\
\hline Huelva & 95 & 12 \\
\hline Santa Cruz de Tenerife & 97 & $\mathbf{3 8}$ \\
\hline Mediterranean Sea ports & $\mathbf{3 0 8}$ & 12 \\
\hline Barcelona & 100 & 13 \\
\hline Tarragona & 101 & 13 \\
\hline Málaga & 107 & $\mathbf{1 0 0}$ \\
\hline Total number of MDH forms & $\mathbf{8 0 2}$ & \\
\hline
\end{tabular}

MDH: Maritime Declaration of Health.

documents are used inappropriately, it may result in an inadequate assessment of public health issues related to international traffic. There is also an IHR List of Authorized Ports to Issue Ship Sanitation Certificates, published and updated by the WHO, that lists all ports each state party has authorised to issue Ship Sanitation Certificates [10]. According to Article 37 of the IHR (2005) [6], 'the master of a ship, before arrival at its first port of call in the territory of a State Party, shall ascertain the state of health on board, and, except when that State Party does not require it, the master shall, on arrival, or in advance of the vessel's arrival if the vessel is so equipped and the State Party requires such advance delivery, complete and deliver to the competent authority for that port a Maritime Declaration of Health which shall be countersigned by the ship's surgeon, if one is carried'. The state party may decide whether it requires all arriving ships to submit a MDH, which should conform to the model provided in Annex 8 of the IHR [6]. For European Union (EU) countries, according to Directive 2010/65/EU, the $\mathrm{MDH}$ is one of the forms that must be submitted to the first European port of arrival [11]. The EU SHIPSAN ACT Information System (SIS), developed within the scope of the EU SHIPSAN ACT Joint Action [12], allows port health authorities to confidentially share completed $\mathrm{MDH}$ forms between EU ports. Seamless and close communication between the master and port health authorities via the MDH enables the latter to detect onboard health problems that might constitute a risk to public health at an early stage and to take immediate measures to reduce the risk of onward transmission [13]. Therefore, it is essential that a MDH form is completed correctly at the onset of the assessment [13].

The International Maritime Organization (IMO) is a specialised agency of the United Nations that is responsible for measures to improve the safety and security of international shipping, and to prevent pollution from ships. One of its conventions, the Convention on Facilitation of International Maritime Traffic (FAL Convention), aims to facilitate maritime transport by simplifying and minimising formalities, data requirements and procedures associated with the arrival, stay and departure of ships engaged in international voyage [14]. The FAL Convention's main objectives are to "prevent unnecessary delays in maritime traffic, to aid co-operation between Governments, and to secure the highest practicable degree of uniformity in formalities and other procedures. In particular, the Convention reduces the number of declarations which can be required by public authorities' [14]. At present, according to FAL Convention, ships may be required to complete nine documents: seven IMO-standardised forms (the General Declaration, Cargo Declaration, Ship's Stores Declaration, Crew's Effects Declaration, Crew List, Passenger List and Dangerous Goods Declaration), one Universal Postal Convention document and one International Health Regulations document (the MDH). Health authorities do not systematically inspect all ships, however, they review all the MDH presented.

Spain's geographical position, and the fact that it is a peninsula with $8,000 \mathrm{~km}$ of coastline with access to the Mediterranean Sea and the Atlantic Ocean, favour the frequent passage of ships [15]. As of 2016, Spain had 33 ports authorised to issue Ship Sanitation Certificates under the IHR [10]. All of these have medical inspectors (port health authorities) to evaluate events that suggest health risks on ships. For these reasons, and because there are numerous ports with high volumes of maritime traffic, cargo and passengers, Spain was considered ideal in terms of studying the quality of MDH forms. 
TABLE 2

Proportion of passenger and cargo ships with properly filled Maritime Declaration of Health forms, Spain, October 2014 to March $2015(\mathrm{n}=802)$

\begin{tabular}{|c|c|c|c|c|}
\hline \multirow[b]{2}{*}{ Fields and questions in MDH forms } & \multicolumn{3}{|c|}{ Properly filled (\%) } & \multirow[b]{2}{*}{$\mathrm{p}$ value } \\
\hline & $\begin{array}{l}\text { Total ships } \\
(n=802)\end{array}$ & $\begin{array}{l}\text { Cargo ships } \\
(n=455)\end{array}$ & $\begin{array}{l}\text { Passenger ships } \\
\qquad(n=347)\end{array}$ & \\
\hline Port of submission & 95 & 92 & 98 & 0.004 \\
\hline Date of submission & 95 & 92 & 99 & $<0.001$ \\
\hline Name of ship & 99 & 99 & 99 & 0.925 \\
\hline Registration/IMO number & 79 & 68 & 93 & $<0.001$ \\
\hline Arriving from & 96 & 93 & 99 & 0.005 \\
\hline Sailing to & 68 & 45 & 97 & $<0.001$ \\
\hline Nationality/flag of ship & 96 & 97 & 95 & 0.048 \\
\hline Master's name & 98 & 98 & 98 & 0.610 \\
\hline Gross tonnage & 85 & 80 & 92 & $<0.001$ \\
\hline Valid Ship Sanitation Certificate & 92 & 90 & 94 & $<0.001$ \\
\hline Place of issue & 95 & 95 & 95 & 0.206 \\
\hline Date of Ship Sanitation Certificate & 95 & 95 & 96 & 0.066 \\
\hline Re-inspection required & 69 & 60 & 82 & $<0.001$ \\
\hline Has ship visited an affected area & 71 & 60 & 86 & $<0.001$ \\
\hline Number of crew members on board & 86 & 94 & 76 & $<0.001$ \\
\hline Number of passengers on board ${ }^{a}$ & 35 & 4 & 76 & $<0.001$ \\
\hline Completely filled nine health questions & 75 & 63 & 90 & $<0.001$ \\
\hline Signed by the master & 85 & 92 & 75 & $<0.001$ \\
\hline Signed by the ship's surgeon ${ }^{a}$ & 32 & 0.4 & 73 & $<0.001$ \\
\hline Date of signature & 86 & 85 & 86 & 0.158 \\
\hline Presence of Attachment to Model of $\mathrm{MDH}^{\mathrm{b}}$ & 10 & 2 & 22 & $<0.001$ \\
\hline
\end{tabular}

IMO: International Maritime Organization; MDH: Maritime Declaration of Health.

a Generally only applicable to passenger ships.

b The presence of an Attachment to Model of MDH indicates that there is at least one case of illness on board the vessel. Thus, this field is only applicable to ships with positive MDHs (health problem(s) on board).

The aim of this study was to examine current $\mathrm{MDH}$ practice, as there are no previous studies on this issue, in order to enable health authorities to improve their capacity to detect and respond to health problems on board ships. For this purpose, we were mainly interested in evaluating whether the MDH forms used by ships conformed to the model set out in Annex 8 of IHR (2005), the extent of the form's completion by ships, and whether there were differences in completion and content depending on the type of ship or the geographical area of the port.

\section{Methods}

\section{Study design}

This was a descriptive study of $\mathrm{MDH}$ forms presented to Spanish ports by ships from all shipping routes. The object of analysis was the MDH form submitted by each ship to port authorities. The study analysed and compared $\mathrm{MDH}$ forms from different types of ships, as well as different MDH types.

\section{Sample size}

We calculated the representative sample size using the following information: in 2014 ca 140,000 ships arrived at Spanish ports [15]. First, we studied $\mathrm{MDH}$ forms presented to port authorities over a 6-month period, from October 2014 to March 2015. Then, based on an estimated population of 70,000 ships over a 6-month period, with a $99 \%$ confidence level and a $5 \%$ margin of error, the calculated minimum sample size was 569 MDH forms.

\section{Participating ports}

Nine of Spain's 33 IHR-authorised ports participated in this study: A Coruña, Santander and Vigo (Atlantic Ocean ports on the northern coast); Algeciras, Santa Cruz de Tenerife and Huelva (Atlantic Ocean ports on the southern coasts and Canary Islands); and Barcelona, Malaga and Tarragona (Mediterranean Sea ports). They were selected based on geography (to obtain information on the different shipping routes) and their inclusion on the IHR list of ports authorised to issue Ship Sanitation Certificates at the time of the study [10]. We requested 100 consecutive $\mathrm{MDH}$ forms 
Proportion of passenger and cargo ships with a Maritime Declaration of Health that conforms to the model provided in Annex 8 of the IHR (2005) and reports on existence of a valid Ship Sanitation Certificate, Spain, October 2014 to March $2015(\mathrm{n}=802)$

\begin{tabular}{|c|c|c|c|c|c|c|c|}
\hline \multirow[b]{2}{*}{ Maritime Declaration of Health form } & \multicolumn{2}{|c|}{$\begin{array}{l}\text { Total ships } \\
(\mathrm{n}=802)\end{array}$} & \multicolumn{2}{|c|}{$\begin{array}{l}\text { Cargo ships } \\
(n=455)\end{array}$} & \multicolumn{2}{|c|}{$\begin{array}{l}\text { Passenger ships } \\
\quad(n=347)\end{array}$} & \multirow[b]{2}{*}{$\mathrm{p}$ value } \\
\hline & $\mathrm{n}$ & $\begin{array}{c}\text { Percentage } \\
\text { of total } \\
(\%)\end{array}$ & $\mathrm{n}$ & $\begin{array}{c}\text { Percentage } \\
\text { of cargo } \\
(\%)\end{array}$ & $\mathrm{n}$ & $\begin{array}{l}\text { Percentage } \\
\text { of passenger } \\
(\%)\end{array}$ & \\
\hline $\begin{array}{l}\text { Conforms to the model MDH (Annex } 8 \text { of IHR } \\
\text { 2005) }\end{array}$ & 624 & 78 & 299 & 66 & 325 & 94 & $<0.001$ \\
\hline $\begin{array}{l}\text { MDH reporting a Ship Sanitation Certificate } \\
\text { issued by an authorised port }{ }^{\mathrm{a}}\end{array}$ & 690 & 86 & 371 & 81 & 319 & 92 & $<0.001$ \\
\hline $\begin{array}{l}\text { MDH reporting a Ship Sanitation Certificate } \\
\text { issued } \leq 6 \text { months before date of } M D H\end{array}$ & 716 & 89 & 384 & 84 & 332 & 96 & $<0.001$ \\
\hline MDH positive & 91 & 11 & 8 & 2 & 83 & 24 & $<0.001$ \\
\hline
\end{tabular}

IHR: International Health Regulations; MDH: Maritime Declaration of Health.

a Port included in the IHR list of ports authorised to issue Ship Sanitation Certificates.

${ }^{b} \mathrm{MDH}$ report on the presence of any health problem on board.

from each port from October 2014 onwards in the order in which they were presented at the port.

\section{Questionnaire to study MDH forms}

Questions and items on the model MDH form (Annex 8 of IHR 2005) include [6]: (i) questions regarding general ship information such as port and date of submission, name of ship, registration/IMO number, port of origin and destination, flag of ship, master's name, gross tonnage, port and date of issue of sanitation control certificate, inspection requirement, visit of affected areas identified by WHO (ports and date), and number of crew members and passengers on board; (ii) health-related questions regarding number of deaths on board due to illness, presence of infectious diseases on board during passage, frequency of ill crew and passengers, presence of ill persons at the time of MDH submission, medical consultation, presence of disease transmission risk factors, control measures taken, presence of stowaways on board, and presence of sick animals on board; (iii) signature of captain, signature of surgeon (if carried), and date of MDH. Finally, for each individual aboard the ship who is ill, the $\mathrm{MDH}$ is to be accompanied by a form called the Attachment to Model of $\mathrm{MDH}$. This attachment requests information about the person's age, sex, nationality, date they joined the ship, nature of illness, date of symptom onset, etc.

Based on the model MDH form [6], we developed a questionnaire to assess the filling in completion and correctness of each field of the MDH forms used by the ships, which are based on but may differ from the model. The answers have been categorised into five options: (i) Yes, correct (field completed and correct); (ii) Yes, wrong (field completed but contains an error); (iii) Yes, unclear (field completed but illegible); (iv) No (field not completed); and (v) Not applicable.
Other questions included in the questionnaire concerned (i) the model of the MDH: based on the format shown in Annex 8 of the IHR (2005) or another format; (ii) the ship type: cargo ship or passenger ship; (iii) the port of submission: A Coruña, Santander, Vigo, Algeciras, Santa Cruz de Tenerife, Huelva, Barcelona, Málaga or Tarragona; (iv) the geographical location of the port: Mediterranean Sea coast, North Atlantic Ocean coast and South Atlantic Ocean coast (Table 1); (v) the 'type' of MDH: positive (health problem(s) on board) or negative (no health problem(s) on board); (vi) the validity of the Ship Sanitation Certificate: yes or no. Yes, if A. and B. below were correct; No, if A. or B. were not correct. A. Ship Sanitation Certificate issued by an authorised port i.e. one included in the IHR list of ports authorised to issue Ship Sanitation Certificates at the time of the study; and B. Ship Sanitation Certificate stated date of expedition less than or equal to 6 months according to Article 39 of the IHR (2005). This period may be extended by one month if the required inspection or control measures cannot be accomplished at the port.

To avoid inter-observer bias, all MDH forms were reviewed by a single observer. Any uncertainty of the single observer was resolved by the first four authors of the study via a specific procedure.

Data were entered and analysed using SPSS 15.0. We undertook descriptive statistics for each variable in the questionnaire. For those variables that could influence the distribution (e.g. type of ship, geographical area of the port and type of $\mathrm{MDH}$ (positive or negative), we used a chi-squared test to study the possible differences in the filling out of the questions on the MDH form in terms of completion and correctness. We studied the measures of association for nominal data: Pearson's contingency coefficient C, Cramer's V 
coefficient and phi coefficient. A value of $p<0.05$ was considered statistically significant.

\section{Results}

We analysed a total of $802 \mathrm{MDH}$ forms submitted to nine selected ports. The ports and geographical areas where the $\mathrm{MDH}$ forms were submitted are shown in Table 1. Regarding these forms, $57 \%(n=347)$ were submitted by passenger ships and 43\% ( $n=455)$ by cargo ships. Table 2 shows the proportion of each document field that was properly (completely and correctly filled), and the differences between cargo and passenger ships. We found that the nine health questions were properly answered in just $75 \%(n=601)$ of the submitted $\mathrm{MDH}$ forms. The question asking whether the ship had visited an affected area was unanswered in $29 \%$ of MDH forms. In addition, $15 \%$ of the forms were not signed by the ship's master, which is required according to Article 37 of the IHR.

As shown in Table 3, the MDH form presented at the ports did not conform to the model provided in Annex 8 in $22 \%$ of 802 ships' MDH documents studied. In most cases, this is because a form following the model in an older Annex 8 of the IHR (2005) was submitted, for example, the model version from the IHR (1969). Furthermore, $86 \%$ of all ships had a Ship Sanitation Certificate issued from an IHR-authorised port and $89 \%$ of all ships had such certificates issued less or equal than 6 months before date of $\mathrm{MDH}$. Of the 802 declarations surveyed, only 91 (11\%) were positive (identifying a health problem on board); 83 from passenger ships and eight from cargo ships. Among those that were positive, seven did not fill out the Attachment to Model of $\mathrm{MDH}$, which is required by the IHR (2005). Acute gastroenteritis, influenza or influenza-like illnesses, and measles were the most frequently reported health issues in the 91 positive $\mathrm{MDH}$ reports $(45 \%, 10 \%$ and $10 \%$, respectively).

Some variables, including ship type, geographical area of the port, and type of $\mathrm{MDH}$, were studied regarding the degree of completion of the document and validity. We found statistically significant associations between the type of ship 'passenger' and the following variables: (i) greater probability that the items of the MDH will be complete (Table 2); (ii) the MDH model is consistent with Annex 8 of the IHR (2005) (Table 3); (iii) the Ship Sanitation Certificate was issued by an authorised port (Table 3); and (iv) the Ship Sanitation Certificate was issued less or equal than 6 months before date of $\mathrm{MDH}$ ) (Table 3 ). The comparison of positive MDHs between cargo and passenger ships could not be carried out because of the low number of positive MDHs from cargo ships. Only five of the analysed variables showed significant differences when positive and negative MDH forms were compared:

- Ship type: only $2 \%(8 / 455)$ of cargo ships issued a positive $\mathrm{MDH}$, while $24 \%(83 / 347)$ of passenger ships did so $(p=0.000)$.
- Invalid Ship Sanitation Certificates because issued from a non-authorised port: 4\% (4/91) of positive $\mathrm{MDH}$ forms and $15 \%(108 / 711)$ of negative forms $(p=0.005)$.

- Invalid Ship Sanitation Certificates because more than 6 months between date of issue and date on the $\mathrm{MDH}$ form: $3 \%$ (3/91) of positive MDH forms and $12 \%(83 / 711)$ of negative forms $(p=0.015)$.

- Missing the signature of the ship's master: $32 \%$ (29/91) of positive MDH forms and 10\% (72/711) of negative forms $(p<0.001)$.

- Missing the next port of destination: $13 \%$ (93/711) of the negative $\mathrm{MDH}$ forms and $3 \%$ (3/91) of positive forms $(p<0.000)$.

When comparing the MDH variables between different geographical areas we found some statistically significant differences. However, these differences disappear if the variable 'type of ship' is introduced in the analysis. Cargo ships are most frequently in the ports on the Atlantic Ocean coast (64\% cargo ships vs $36 \%$ passenger ships) and passenger ships are most frequently in the ports on the Mediterranean Sea coast ( $55 \%$ passenger vs $45 \%$ cargo) $(p<0.001)$.

\section{Discussion}

There are a few studies to date that analyse compliance with the IHR (2005) recommendations and the use of related documents. In 2011, Hadjichristodoulou et al. [9] reported that the $\mathrm{MDH}$ was the main reporting tool used for the surveillance and monitoring of communicable diseases on passenger ships in Europe. However, only $30 \%$ of the 59 competent authorities surveyed reported that they require all arriving ships to submit $\mathrm{MDH}$ forms. In special situations of health surveillance, as in during the early stages of pandemic influenza $A$ in 2009 , Schlaich et al. [16] showed that $32 \%$ of shipping companies experienced one or more health screening measures by port health authorities. Furthermore, a request to complete the MDH form was reported by $23 \%$ of the companies that participated in the study (7/31).

As of 2016, 115 of 171 IMO members have acceded to the FAL Convention [14]. The FAL Convention and Directive 2010/65/EU of the European Parliament and of the Council have included the MDH document among the nine documents that all ships must electronically submit (promptly and correctly filled out) if requested to do so by port authorities $[11,14]$. Furthermore, several studies recommend greater and better use of the $\mathrm{MDH}$ as modelled in Annex 8 of the IHR (2005) [1719]. Our results show that a high proportion of the $\mathrm{MDH}$ forms submitted did not conform to the 2005 model (22\%), have incomplete information on relevant data (only $75 \%$ completed the nine health questions) or have invalid Ship Sanitation Certificates (ca 1 in 5 cargo ships and 1 in 10 passenger ships) because the 
date of issue was $\geq 6$ months and/or the port was not authorised. The communication of any condition on board a ship (gastrointestinal illness, haemorrhagic fevers, respiratory diseases, etc.) to port health authorities via the MDH form provides the opportunity for more efficient responses, including making a faster diagnosis, disembarking patients, identifying contacts and facilitating the adoption of health measures [20]. An incomplete $\mathrm{MDH}$ makes it difficult to assess risks and requires additional communication with the ship to obtain the missing information. Such omissions lengthen the response time, and reduce the effectiveness and efficiency of monitoring. This highlights the importance of fully completing the MDH form for the early detection of events and for timely implementation of public health measures on board ships, as per the WHO requirements [3].

Cargo ships require greater attention by the port health authorities as our study shows that their MDH forms are more frequently incomplete. Unlike passenger ships, freighters often lack medical services, make longer journeys and use multiple shipping routes, which can hinder the management of diseases.

Usually, when a correct and complete MDH informs the port health authorities of communicable diseases or other potential public health problems, competent authorities assess the information, confirm the situation on board and propose appropriate measures for each situation, such as isolation, landing, disinfestation, decontamination and vaccination.

It should be considered as a limitation that this study was unable to determine if all ships with potential health risks on board recorded this information on a MDH form because health authorities do not systematically inspect all ships. In addition, given that descriptive studies often represent the first scientific dip into new areas of inquiry, the limitations of this study must be addressed in subsequent analytical studies [21]. Further studies are required to assess whether the $\mathrm{MDH}$ is, in practice, a reliable reporting tool. For this, it would be necessary to inspect all ships arriving at ports, interview masters or doctors on board, and check whether the information recorded on $\mathrm{MDH}$ forms represents the reality on board; however, this is not a feasible goal.

\section{Conclusions and recommendations}

The $\mathrm{MDH}$ document brings together information to assess the state of health on board a ship. Its proper completion is key to conducting a preliminary risk assessment, and efforts should be made to achieve this goal. Thus, masters and specific crew members should be properly trained to complete the MDH in such a way that port health authorities can assess the situation in advance.

We believe that an improvement in the current use of the $\mathrm{MDH}$ will result in improved risk assessment, greater confidence in the information provided and improve the trust between ships, health authorities and other stakeholders in the port, such as conveyance operators, relevant port authorities and surveillance system operators. Monitoring the implementation of the IHR (2005) guidelines related to the MDH should not only include monitoring the use of appropriate communication channels, but also an evaluation of the quality of the information provided. In later phases, the proper use of the MDH should be assessed and measured to prevent and provide a public health response to the international spread of disease.

Several countries might be involved in the response to an outbreak on board a ship. Therefore, the MDH should not be considered an isolated document concerning only one country, but a source of information that should be shared between port health authorities for follow-up action. The use of the SIS, a tool developed by the EU SHIPSAN project for the immediate sharing of information between ports, should be encouraged for the transmission of such information. Further, training masters on the importance of the $\mathrm{MDH}$ and how to routinely use it would also help facilitate prompt responses in the case of a complex public health event occurring on their ships.

Finally, further studies should be conducted to assess the real value of the MDH as a public health assessment tool for events on ships. One such avenue could be the analysis of the consequences to public health when the MDH is not properly completed.

\section{Acknowledgements}

The authors greatly appreciate the suggestions made by experts: Daniel Menucci, Christos Hadjichristodoulou, Varvara A Mouchtouri, Martin Walker, Martin Dirksen and André Jacobi. We also wish to acknowledge the support of the Asociación de Médicos de Sanidad Exterior (AMSE) for review and translation of the manuscript, and María Coronado Martín for translation of the manuscript.

Conflict of interest

None declared.

Authors' contributions

All authors have contributed directly to the intellectual content of the paper. Particular contributions are as follows: RM López-Gigosos, M Segura, RM Díez-Díaz, I.Ureña and $M$. Dávila have developed the concept of the manuscript, have managed the database, analysed the data and have wrote the first draft. D.Urzay, P.Guilloy, A.Guerra-Neira, A.Ribera, A.Perez-Cobaleda, A.Martín., M.Nuñez-Torrón, B. Alvarez, M. Faraco, JM Barrera, MJ Calvo, J. Gallegos, A. Bermejo, and C. Aramburu, contributed to the study with data from their respective ports, analysis of data and, provided comments on the final manuscript. M. Dávila., F. Carreras, and $R$. Neipp have been involved in the planning and design of the scheme, have participated in the analysis and interpretation the results critically and have revised the article for important content. A. Mariscal provided epidemiological 
expertise, and also has made a substantial contribution to final revision.

\section{References}

1. World Health Organization (WHO). The World Health Report 2007 - A safer future: global public health security in the 21st century. Geneva: WHO; 2007. Available from: http://www.who. int/whr/2007/en/

2. Ziemann A, Rosenkötter N, Riesgo LG-C, Fischer M, Krämer A, Lippert FK, et al. Meeting the International Health Regulations (2005) surveillance core capacity requirements at the subnational level in Europe: the added value of syndromic surveillance. BMC Public Health. 2015;15(1):107. DOI: 10.1186 S12889-015-1421-2 PMID: 25879869

3. World Health Organization (WHO). Handbook for management of public health events on board ships. Geneva: WHO; 2016. Available from: http://www.who.int/ihr/ publications/9789241549462/en/

4. Merianos A, Peiris M. International health regulations (2005). Lancet. 2005;366(9493):1249-51. DOI: 10.1016/So1406736(05)67508-3 PMID: 16214586

5. Hill CD. Cruise ship travel. In: Keystone JS, Freedman DO, Kozarsky PE, Connor BA NH, editors. Travel Medicine. 3rd ed. Philadelphia: Elsevier Saunders; 2013.

6. World Health Organization (WHO). International Health Regulations (2005) 3rd ed. Geneva: WHO; 2005. Available from: http://www.who.int/ihr/publications/9789241596664/ en/

7. Centers for Disease Control and Prevention (CDC). CDC Health Information for International Travel 2010: The Yellow Book. Maryland Heights: Elsevier Mosby; 2009. Available from: http://www.sciencedirect.com/science/book/9780702034817

8. Chang M. WHO Director-General addresses the Review Committee of the International Health Regulations focused on the Ebola response. Geneva: World Health Organization. 24 Aug 2015. Available from: http://www.who.int/dg/ speeches/2015/review-committee-ihr-ebola/en/

9. Hadjichristodoulou C, Mouchtouri VA, Martinez CV, Nichols $\mathrm{G}$, Riemer T, Rabinina J, et al. Surveillance and control of communicable diseases related to passenger ships in Europe. Int Marit Health. 2011;62(2):138-47.PMID: 21910118

10. World Health Organization (WHO). List of ports and other information submitted by the States Parties concerning ports authorized to issue Ship Sanitation Certificates unde the International Health Regulations (2005). Geneva: WHO; 2017. Available from: http://www.who.int/ihr/ports_airports/ portslanding/en/

11. European Parliament, Council of the European Union. Directive 2010/65/EU of the European Parliament and of the Council of 20 October 2010 on reporting formalities for ships arriving in and/or departing from ports of the Member States and repealing Directive 2002/6/EC. Official Journal of the European Union. Luxembourg: Publications Office of the European Union. 29.10.2010: L 283. Available from: http://eur-lex.europa.eu/ legal-content/en/ALL/?uri=CELEX\%3A32010L0065

12. SHIPSAN. The EU SHIPSAN ACT Joint Action. Larissa: SHIPSAN. [Accessed 31 May 2017]. Available from: http://www.shipsan. eu

13. Mouchtouri VA, Nichols G, Rachiotis G, Kremastinou J, Arvanitoyannis IS, Riemer T, et al. State of the art: public health and passenger ships. Int Marit Health. 2010;61(2):4998.PMID: 21154293

14. International Maritime Organization (IMO). Convention on Facilitation of International Maritime Traffic (FAL). London: IMO. [Accessed 1 Jun 2017]. Available from: http://www. imo.org/en/About/conventions/listofconventions/pages/ convention-on-facilitation-of-international-maritime-traffic(fal).aspx

15. Ministerio de Fomento. Estrategia logística de España. [Logistics Strategy of Spain]. Madrid: Ministerio de Fomento. 25 Nov 2015. Spanish. Available from: http:// www.fomento.gob.es/MFOM/LANG_CASTELLANO/PLANES/ ESTRATEGIA_LOGISTICA/

16. Schlaich C, Gau B, Cohen NJ, Kojima K, Marano N, Menucci $D$. Infection control measures on ships and in ports during the early stage of pandemic influenza $A\left(\mathrm{H}_{1} \mathrm{~N}_{1}\right) 2009$. Int Marit Health. 2012;63(1):17-23.PMID: 22669808

17. Low A, Hüsing UP, Preisser A, Baur X. Regulations and control of in-transit fumigated containers as well as of fumigated cargo ships.Int Marit Health. 2003;54(1-4):77-85.PMID: 14974780

18. Hadjichristodoulou C, Mouchtouri VA, Guglielmetti P, Lemos CM, Nichols G, Paux T, et al. Actions for prevention and control of health threats related to maritime transport in European Union. Travel Med Infect Dis. 2013;11(4):238-42. DOI: 10.1016/j.tmaid.2013.02.001 PMID: 23518234

19. Katz R, Dowell SF. Revising the International Health Regulations: call for a 2017 review conference.Lancet Glob Health. 2015;3(7):e352-3. DOI: 10.1016/S2214-109X(15)00025-X PMID: 25960266

20. Westlund K. Infections onboard ship--analysis of 1290 advice calls to the Radio Medical (RM) doctor in Sweden. Results from 1997, 2002, 2007, and 2009. Int Marit Health. 2011;62(3):191-5. PMID: 22258846

21. Grimes DA, Schulz KF. Descriptive studies: what they can and cannot do.Lancet. 2002;359(9301):145-9. DOI: 10.1016/S01406736(02)07373-7 PMID: 11809274

\section{License and copyright}

This is an open-access article distributed under the terms of the Creative Commons Attribution (CC BY 4.0) Licence. You may share and adapt the material, but must give appropriate credit to the source, provide a link to the licence, and indicate if changes were made.

This article is copyright of the authors, 2017. 